\title{
Lessons for GIS Implementation in Zimbabwe from the South African Experiences
}

\author{
Kudzayi Savious Tarisayi
}

\begin{abstract}
In recent years Geography Information System (GIS) implementation in schools has emerged as one of the most important threads deserving academic inquiry globally. This paper seeks to draw lessons from the South African experience on GIS implementation by engaging in an in-depth documentary analysis of the Geography syllabus in the updated Zimbabwe curriculum and the South Africa (SA) Curriculum and Assessment Policy Statement (CAPS) Geography syllabus. This paper draws from the Normalisation Process Theory (2009) and the Extended Normalisation Process Theory (2013). The researcher purposively selected the Ordinary Level Geography Syllabus in Zimbabwe and CAPS Geography Syllabus Grade 10 - 12. This paper argues that there are numerous lessons that Zimbabwe can draw from South African experiences. Among the lessons that can be drawn from the CAPS Geography syllabus are the following; the fusion of GIS across Geography topics instead of taking GIS as a standalone topic; allocating adequate financial resources to schools, allocating GIS more time in the syllabus among others. The researcher recommends that Zimbabwe adopt a paper-based GIS educational package.
\end{abstract}

Keywords: Geography Information System, updated Zimbabwe curriculum, Curriculum and Assessment Policy Statement

\section{Introduction}

This paper on GIS implementation in schools draws lessons from the South African experience by engaging in an in-depth documentary analysis of the 


\section{Kudzayi Savious Tarisayi}

Geography syllabus in the updated Zimbabwe curriculum and Curriculum and Assessment Policy Statement (CAPS) Geography syllabus. For comparative purposes, the researcher purposively selected the Ordinary Level Geography Syllabus in Zimbabwe and CAPS Geography Syllabus Grade 10 - 12. A number of studies (Drew, 2012; Dardagan, 2013; Jansen, 2017) have offered comparisons of the Zimbabwean and South African education system. However, it can be noted from these studies that there is no comparison of the Geography syllabi in schools in Zimbabwe and South Africa as pursued in this paper. Drew (2012) states that the education systems in Zimbabwe and South Africa allow for comparability due to a number of reasons. Zimbabwe and South Africa's shared colonial history has implications on the present-day education systems of the two countries. The most glaring similarity in the education arena is that both countries inherited racially skewed education systems. The majority black population were denied educational opportunities in both countries. However, tremendous efforts to redress the colonial legacy in the education system in the post-independence era were witnessed in both countries albeit with varying implications. Efforts have also been exerted to modernise the education sector through curriculum change. One of these changes has been the introduction of GIS into the Geography curriculum in both SA and Zimbabwe.

\section{What is GIS?}

GIS is a product of the computer revolution which entailed the computerisation of various sectors of the economy. Palladino (1994:04) reveals that, 'Geographic information systems are an outgrowth of the computer revolution, as automated versions of the age-old activity of analysing our surroundings'. Ozgen (2009:1879) states, 'A Geographic Information System (GIS) is a high performance computer-aided chain of software which enables us to understand, interpret, capture, update, map, and display natural and human-originated events on Earth and allows us to bring out such phenomena in a form of synthesis'. Whereas, Burrough (1986:06) avers that GIS is 'a powerful set of tools for collecting, storing, retrieving at will, transforming, and displaying spatial data from the real world for a particular set of purposes'. Thus, GIS is a computer-based platform that integrates a multiplicity of data sets to digitally represent and analyse the geographic features present on the Earth' surface and 
the events. In addition, GIS typically comprises hardware, software, geographic data, and personnel designed to manipulate geographically referenced information in order to achieve a stated objective (Breetzke, Eksteen \& Pretorious 2011:02). According to Whitaker (2011:52), 'GIS software is the tool that sets the stage for teachers to use GIS to build inquiry, 'hands-on, minds-on' lessons and projects that are correlated to specific content objectives'. Hence, GIS can be viewed as a tool aiding analysis of the Earth's surface and events in Geography.

\section{Curriculum Change in Zimbabwe and South Africa}

Curriculum change in both countries introduced GIS in Geography as stated above. In Zimbabwe GIS is now being taught from Form One to Form Six (Curriculum Development Unit 2015) whilst in South Africa, GIS is covered in the curriculum from Grade 10 to 12 . The paper focuses on GIS implementation from Form One to Four in Zimbabwe and Grade 10 to 12 in South Africa. An interrogation of GIS implementation in Zimbabwe by drawing lessons from South African experiences is proffered through a documentary analysis of the available curricula and empirical research that have been published. The paper starts by providing a background to GIS implementation in Zimbabwe. The next section introduces to the reader to the concept of GIS as well as selected literature from around the world on GIS implementation to provide a foundation for understanding GIS implementation in Geography world-wide. The researcher proceeds to present the research methodology and then finally presents the themes around GIS implementation in Zimbabwe from South African experiences. The paper finally presents some valuable concluding remarks from the discussion.

\section{Background to GIS Implementation in Zimbabwean Schools}

GIS implementation in Zimbabwean schools was introduced as part of the updated Zimbabwean curriculum in 2017. The introduction of an updated curriculum in Zimbabwe brought numerous changes in the syllabi in secondary education in general and Geography in particular (Curriculum Development Unit 2015). The government of Zimbabwe in 2015 initiated a curriculum review process with the aim to enhance the school curriculum against the 


\section{Kudzayi Savious Tarisayi}

backdrop of the Presidential Commission of Enquiry into Education and Training Report (Nziramasanga 1999). Various stakeholders participated in the curriculum review process across the country. Learners, parents, teachers, leaders in industry, academia, media among others participated in the curriculum review process. Thus, numerous recommendations were made by stakeholders during the review process which culminated in the inclusion of new concepts and teaching approaches in the curriculum (Ministry of Primary and Secondary Education 2015b). The need to innovate and integrate Information Communication and Technology in the education sector was among the recommendations made by the stakeholders (Ministry of Primary and Secondary Education 2015b). Among the notable changes introduced by the updated curriculum in Zimbabwe was the introduction of Geographic Information Systems (GIS) in secondary education. Other notable changes brought about by the updated curriculum which have a bearing on Geography teaching include the introduction of continuous assessment and emphasis on practical lessons as opposed to theoretical lessons. Conversely, this paper focuses on the lessons from South Africa that can be learnt in GIS implementtation.

Notwithstanding the acknowledgement and advocacy by geographers around the world on the importance of GIS in secondary education (Kerski 2003; Lam, Lai \& Wong 2009), Zimbabwe has been lagging behind in GIS implementation as reflected by its glaring absence from the schools prior to the updated curriculum. The position adopted by the Zimbabwe government on GIS implementation is supported by scholars, Gardner and Lambert (2007) who argue that 'the curriculum needs to provide opportunities for pupils to use varied resources, including maps, visual media and Geographical Information Systems' (Gardner \& Lambert 2007:07). GIS prior to the adoption of the updated curriculum in Zimbabwe was only being introduced at tertiary level, which is at teachers' colleges and universities. Thus, student-teachers and undergraduates were introduced to GIS without any prior exposure to the sub discipline at secondary school level. The new secondary school Geography syllabus which was introduced in Zimbabwe states that learners should 'demonstrate basic knowledge of geographic information systems (GIS) in resource management' (Curriculum Development Unit 2015:01). Therefore, this article was premised on examining the challenges availed by the implementation of GIS in secondary schools in Zimbabwe. The challenges are discussed in the light of South African experiences in GIS implementation. 


\section{GIS Implementation Abroad}

A number of studies have been carried around the world on the implementation of GIS in secondary education. In a study in the US secondary schools, Kerski (2003) established that GIS was peripheral in the secondary school education and that there were fewer GIS-based modules. Therefore, it can be noted from Kerski's study that GIS implementation in USA was still in its infancy as only $1 \%$ of the high schools are now using GIS technology. In addition, Kerski's study further noted that lesser than $5 \%$ of all US secondary schools owned GIS software. In another study in Hong Kong, Lam et al. (2009) revealed that the level of use of GIS in secondary education was low despite the availability of the essential hardware and software in schools. Thus, it can be argued that GIS implementation in schools takes more than just the availability of essential hardware and software. Availability of hardware and software are prerequisite but other factors such as time allocation and teacher competency also need to be available. A study by Komlenović, Manić and Malinić (2013) in Serbia noted that GIS is not yet fully utilised in secondary education. The study by Komlenović et al. (2013) further note that the use of GIS was theoretical as teacher presentation was the dominant method. These studies reviewed above can be argued to have been carried out in countries in the north, thus it becomes imperative that studies in the south on GIS are carried out to fill the gap in the literature. There are studies on the implementation of GIS in South Africa (Breetzke et al. 2011; Chisholm, Hoadley, wa Kivulu, Broakes, Prinsloo, Kgobe, Mosia, Narsee \& Rule 2005; Marais 2016). Therefore, there was a need for another study on GIS implementation in a country that shares historical and educational realities with Zimbabwe. Hence, this paper focusing on GIS in Zimbabwe on the adoption of GIS in secondary education drawing lessons from South African GIS implementation experience.

\section{Theoretical Framework}

This paper on the lessons on GIS implementation in Zimbabwe drawn from the South African case study is guided by the Normalisation Process Theory (2009) and the Extended Normalization Process Theory (2013). The Normalization Process Theory is an implementation theory seeking to appreciate and unpack certain aspects of implementation of policy or intervention. The researcher views GIS implementation as an intervention 
aimed at enhancing Geography teaching and learning in Zimbabwe and South Africa. May and Finch (2009) reveal that the Normalisation Process Theory articulates factors that facilitate and obstruct the integration of complex interventions into everyday practice. Additionally, the Normalisation Process Theory has four main components; coherence, cognitive participation, collective action and reflexive monitoring (Hooker, Small, Humphreys, Hegarty \& Taft 2015; May \& Finch 2009). Therefore, the Normalisation Process Theory in this paper guides sense-making of GIS and engagement of stakeholders in GIS implementation. Furthermore, the Normalisation Process Theory states that the 'drivers of change include individual, organisational, political and economic factors' (Grol \& Wensing 2004: 13). The Extended Normalisation Process Theory seeks 'to provide a more comprehensive explanation of the constituents of implementation processes' (May 2013: 1). Additionally, according to the Extended Normalisation Process Theory (2013) implementation of intervention comprises practitioners who interact with each other and with intervention components and the implementation contexts. Hence, the researcher draws from the Normalisation Process Theory (2009) the benefits and costs of an intervention. Whereas, from the Extended Normalisation Process Theory, the researcher is guided on role of the practitioners in the implementation process.

\section{Research Methodology}

The data for this paper encapsulates the lessons on GIS implementation in Zimbabwe that can be drawn from the South African case study. Stake (1995) identifies three types of cases which are dependent on the purpose of inquiry; 'an instrumental case study is used to provide insight into an issue; an intrinsic case study is undertaken to gain a deeper understanding of the case. The collective case study is the study of a number of cases in order to inquire into a particular phenomenon' (Zucker 2009: 3). Thus, the South African case was selected as an instrumental case into GIS implementation in schools in Zimbabwe. I utilised documentary analysis. Bowen (2009) avers that document analysis entails researcher giving an expression and import to documents. Documentary analysis has three primary types; public records, personal documents and physical evidence (O'Leary 2014). In this paper, the researcher utilised public documents; studies carried out in South Africa on 
GIS implementation, the South African National Curriculum and Assessment Policy Statement (CAPS) Geography syllabus Grade 10 - 12 and the Zimbabwean Geography Syllabus Forms 1 - 4. The study was confined to a documentary analysis of public documents as Bowen (2009) argues that document analysis focuses on quality rather than quantity. Emerging themes from the documentary analysis on lessons drawn from the South African experience were identified and is articulated below.

\section{Lessons from Studies on GIS Implementation in South Africa}

The National Curriculum Statement (NCS) for Grades 10 - 12 introduced GIS into South African schools as part of the Geography curriculum from 2006 2008 (Breetzke et al. 2011) The implementation of CAPS further treasured the place of GIS in the South African geography curriculum. Whereas, in Zimbabwe, GIS was only introduced in 2017 as part of the updated Zimbabwean school curriculum. It can thus be noted that South Africa has been teaching GIS for more than a decade. Therefore, it follows that South African experiences can avail invaluable lessons to the Zimbabwean education system. Breetzke et al. (2011: 3) reveal, 'Anecdotal evidence suggests that the recent introduction of GIS in schools in South Africa has been problematic'. Hence, the researcher seeks to draw lessons from the problems encountered by South African schools in the introduction of GIS.

\section{Financial Constraints in GIS Implementation}

A growing thread on the GIS implementation in South Africa argues that the introduction of GIS was curtailed by financial constraints. Among scholars who contributed to this growing thread are Zuma (2016), Breetzke et al. (2011) and Nxele (2007). A study by Zuma (2016) found that lack of funding from the Department of Education hindered GIS implementation in the uMhlathuze Circuit. Nxele (2007) avers that there is lack of funding in schools which adversely affects GIS implementation. Funding is instrumental in GIS implementation in schools as it has a bearing on the schools' ability to procure hardware and software. Breetzke et al. (2011: 7) elaborate, 'The introduction of computerized GIS in any schooling system requires considerable financial input in terms of purchasing the necessary software, hardware, and educational 
materials as well as money for the training of educators'. Essential for this paper is that successful GIS implementation in schools is hinged on financial input from the stakeholders. Therefore, it can be argued from the lesson here drawn from the South African case study is that GIS implementation in schools requires substantial funding. Despite an acknowledgement by this researcher that the Zimbabwean curriculum by adopting GIS is heading in the right direction, it should be noted that there is a need for adequate funding. In addition, an innovation in the nature of GIS implementation in schools requires an increase in the financial resources allocation.

\section{Lack of Electricity}

Anecdotal evidence emerging from studies on GIS implementation in South African schools also reveal that lack of electricity in some schools is another challenge to GIS implementation. A study by Nxele (2007) found that $41 \%$ of the schools in Eastern Cape do not have electricity. Rural schools are the most affected by lack of electricity due to the fact that they are located in communities which are still lagging behind in development. This is in spite of the South African Schools Act (SASA) of 1996 stipulating that each school should have electricity among other prerequisite infrastructure. Thus, it can be argued that GIS implementation in South Africa was curtailed by the lack of electricity in some schools. Resultantly, there was no uniform GIS implementation throughout the country as schools without electricity were lagging behind. Therefore, an important lesson that can be drawn from the South African experience is that GIS implementation can be affected by lack of electricity. In order for GIS implementation to be successful in Zimbabwe, the relevant authorities should strive to electrify all schools. Tarisayi (2010) revealed that ICT integration in Masvingo district was hampered by lack of electricity among other issues. Another study by Konyana and Konyana (2013) found that computerization in rural schools in Zimbabwe was hampered by lack of electricity. Therefore, it remains to be seen how the Zimbabwean schools are going to implement GIS uniformly against a background of lack of electricity in most rural schools. The realisation of the magnitude of challenges posed on GIS implementation by a lack of electricity led geographers and scholars in South Africa to consider a paper based GIS educational package. Breetkze et al. (2011) recommend a paper-based GIS as a practical solution to overcome GIS implementation challenges in South Africa. Therefore, the 
researcher argues that another important lesson on GIS implementation from the South African experience is adopting a paper-based GIS. A paper-based GIS has the advantage of being suitable for resource constrained schools in developing countries like South Africa and Zimbabwe.

\section{Time Allocation}

The time allocation for GIS in Geography lessons has also been identified as a challenge to GIS implementation by scholars (Breetzke et al. 2011). Time constraints in the teaching of GIS in South Africa stems from the CAPS allocation of only four hours per week to teaching Geography. Resultantly it can be argued that Geography as an elective in the CAPS curriculum has been allocated inadequate time. Therefore, the teaching of GIS becomes theoretical without any exposure to the technical and practical aspects of GIS which is time consuming. Furthermore, time constraints also have implications on staff development as Geography teachers lack the time to attend GIS workshops and training (Breetzke et al., 2011). Hence, as Zimbabwe innovates and introduces GIS there is need to circumspect and introspect on the time needed for both teaching GIS and staff developing of teachers to be competent in their teaching of GIS as it is a new sub discipline of Geography and teachers have not had exposure to it in their preservice training. The updated Zimbabwean Geography syllabus allocates only five lessons per week which translates to three hours and twenty minutes. Hence, the time allocated to Geography in the Zimbabwean updated curriculum based on lessons from South African experience can be argued to be inadequate. The South African experience indicates that GIS implementation in schools was curtailed by time constraints and therefore it follows that the same scenario is bound to happen in Zimbabwe. The researcher poses the question; If South Africa had challenges working with four hours per week, what are the implications of Zimbabwe's allocation of three hours and twenty minutes? Thus, time allocated to the teaching of Geography will become a stumbling block in GIS implementation as revealed by lessons from South African experiences. Hence, the researcher argues that there is need to address the time allocation for the teaching of GIS in Geography in both countries, it appears.

\section{Class Size}

Studies on GIS implementation in South Africa also reveal that class sizes are 
another hindrance. In terms of South African education policy, learner: educator ratios are pegged at 1:40 for primary schools and 1:35 for secondary schools. A study by Marais (2016) revealed that South African schools are overcrowded. In addition, Chisholm et al. (2005: 20) elaborate,

Large classes impact on workload, in so far as the assessment, recording and reporting and other requirements are increased manifold - the result is that educators with large classes spend more time on discipline and related issues than on meeting the requirements, which become well-nigh impossible in contexts with limited resources.

Implementing GIS in such an overcrowded learning environment becomes a daunting task for the Geography teacher. Thus, it can therefore be reasoned that GIS implementation in South African schools is adversely affected by large class sizes to a great extent. GIS lessons requires a development of practical skills as opposed to theoretical approaches which are suitable for large class size. Hence, it can be argued from lessons drawn from the South African experience that GIS implementation requires an optimum class size. The challenge of class size can be addressed through long terms measures such as the construction of more schools and employing more teachers. Employing more teachers will address the teacher: pupil ratio (the current teacher: pupil ratio is at 1:50 in Zimbabwe according to Ministry of Primary and Secondary Education 2015a) while constructing more schools will address overcrowding in classrooms.

\section{Lessons Drawn from the CAPS Geography Grade 10 - 12 Syllabus in South Africa}

This section analyses lessons that can be drawn the CAPS Geography Grade 10 - 12 syllabus in South Africa. The lessons that are analysed in this section are legal framework, political will, aims of the syllabus, integration of GIS and elective status of Geography.

\section{Legal Framework}

Curriculum change requires a supporting legal framework. A crucial lesson on GIS implementation from the South African experience is on the role played 
by a supportive legal framework. The researcher noted that the CAPS adoption in South African schools is within the legal framework. The CAPS implementation is supported by the South African constitution as well as the South African Schools Act (SASA) of 1996. Hence, the researcher argues that any innovation of the magnitude of GIS implementation in schools requires a supporting legal framework as revealed by the South African experiences. Therefore, it follows that it is imperative that the Zimbabwean education system ensure that there is a supportive legal framework to enhance GIS implementation. A supportive legal framework is crucial in ensuring that there is government support and funding in the rollout of GIS implementation. The above section argued that GIS implementation in South Africa was curtailed by lack of financial resources and electricity. These challenges can be addressed through adherence to the legal framework (South African Schools Act (SASA) of 1996) which stipulates that all schools should have electricity. In addition, the legal framework also specifies the role and contribution of each and every stakeholder in the funding of educational innovations such as GIS implementation to a greater extent.

\section{Political Will}

Another important lesson from the South African experience which was noted is that educational programmes in general and GIS implementation in schools particular requires political will. Most of the challenges already discussed in the earlier sections can be overcome with a strong political will. The political will necessary for the success of GIS implementation is aptly summed by the current South African Minister of Basic Education Angie Motshekga;

Curriculum reform is not something that the system takes lightly. My message from the onset of the curriculum review process has been that we need to work against change fatigue in order to build confidence and enthusiasm amongst all our stakeholders. Therefore, we are proceeding deliberately and decisively to effect the broad recommenddations of the Ministerial Committee. At the same time, we need to deal quickly and efficiently with curriculum implementation challenges and difficulties that do exist (Motshekga 2010).

Thus, according to the South Africa minister of Basic Education, curriculum 


\section{Kudzayi Savious Tarisayi}

reform is prioritized by her ministry. Additionally, Motshekga warns against curriculum review fatigue as it was a long and demanding process. It can thus be argued that GIS implementation in schools in South Africa was carried out with the support of the minister and the government in its totality. Hence, the researcher's argument that one important lesson that can be drawn on GIS implementation from South Africa experience is the role played by political will. Therefore, any discussion on the challenges faced in GIS implementation in schools in South Africa calls for an appreciation of the contribution of political will. It can thus be argued further that for Zimbabwe to succeed in avoiding the pitfalls encountered in South Africa there should be political will, a commitment by government to ensure the success of a new curriculum innovation in the curriculum.

\section{Aims of the Syllabus}

Another essential lesson that can be drawn from the South African experience pertains to aims of the syllabus. The Zimbabwean Updated Geography Syllabus (2016:01) states that learners should 'demonstrate basic knowledge of geographic information systems (GIS) in resource management'. Whereas, the CAPS Curriculum (Grade 10 - 12) states, 'promoting the use of new technologies, such as Information Communication Technology (ICT) and Geographical Information Systems (GIS)'. The CAPS policy document is clear in terms of its GIS objective as compared to the Zimbabwean updated curriculum. The objective of the CAPS Curriculum clearly shows that there is indeed a commitment towards GIS implementation in South Africa schools. In addition, a comparison of the two aims reveals that South Africa pursues practical use of GIS while Zimbabwe is still striving for theoretical knowledge of GIS. Hence, there is a need to realign the aims of The Zimbabwean Geography syllabus towards promotion of the use of new technologies.

\section{Integration of GIS}

The documentary analysis further revealed disparities in the approaches in GIS implementation in South Africa and Zimbabwe. In the CAPS Curriculum Grade 10 - 12 Geography syllabus, GIS is not taught as a standalone topic but is supposed to be included and applied in various topics. For example, GIS is 
applied in every topic at Grade 12 while for Grade 10 it is applied to the topic on water resources and at Grade 11 it is applied to resources and sustainability. Therefore, it can be argued that by the end of the Geography course from Grade 10 up to Grade 12, GIS would have been applied to all topics. However, in the Zimbabwean Geography syllabus there is a different approach altogether whereby GIS is taught as a standalone topic from Form 1 - 4. GIS is not integrated in the Zimbabwe Geography curriculum into each of the themes but is introduced as a separate topic. In addition, GIS in the Zimbabwean Geography syllabus comes at the end of the curriculum. The Zimbabwean approach to GIS implementation can be argued to relegate GIS to an addendum. Teachers can avoid teaching GIS in the Zimbabwe scenario because it comes at the end of the curriculum and it is also a standalone topic. Thus, an important lesson on GIS implementation that can be drawn from the South African experience is on the need to integrate GIS in all topics in Geography. An appreciation of GIS can only be made possible if learners are constantly being taught GIS concepts throughout their Geography curriculum. Reserving GIS to one standalone topic can be argued to be demeaning its purported contribution to Geography. Furthermore, some teachers may opt not to teach GIS if it is not integrated into other topics in the syllabus.

\section{Elective Status of Geography}

The documentary study also noted that Geography is an elective in both countries. In Zimbabwe, prior to the introduction of the updated Zimbabwe curriculum Geography was a compulsory subject. However, it was downgraded to an elective status in the updated curriculum. Geography is also an elective in the South Africa CAPS curriculum. Some of the challenges faced in South African schools already discussed in detail above are attributable to the subject's elective status. For instance, studies by Nxele (2007) and Zuma (2016) all established that GIS implementation was curtailed by a lack of funding. In addition, another study by Breetzke et al. (2011) indicated that time constraints affected GIS implementation in South Africa. Lack of funding and time constraints can all be associated with the elective status of Geography in the curriculum as a subject. Thus, the updated Zimbabwean curriculum can be argued to have the following outcome best explained with the idiom: 'given with one hand and taken away with the other'. The inclusion of GIS in the 
updated curriculum was welcome. However, making Geography an elective is not good for the subject as it leads to attitudinal problems from the learners and administrators. West (2009) opines that GIS implementation is curtailed by student negative attitudes. GIS implementation will therefore suffer from negative attitudes from administrators due to its financial demands. Resultantly, it can be argued that administrators would rather promote other subjects which have less financial demands as compared to Geography. Hence, it can be argued that strides likely to be accomplished by the inclusion of GIS in Geography are likely to be reversed by the change in the status of the subject. The downgrading of the status of Geography to an elective has ramifications for resource allocation and timetabling. Less financial and material resources are allocated electives in schools as shown in the South African experience. Thus, Geography has fallen victim to its new elective status which means less resource allocations. Hence, it can be argued that while the inclusion of GIS in the updated Zimbabwean curriculum is applauded, downgrading of the status of the subject to an elective is mourned to a greater extent. The likely benefits of the enhancement of the Geography syllabus in Zimbabwe will be eroded by the elective status now accorded to the subject to a greater extent. Therefore, the fact that Geography has an elective status in the curriculum has far reaching implications in GIS implementation in Zimbabwe. The South African experience indicate that a lack of funding and time allocation issues currently inhibits GIS implementation and can be resolved through making the subject compulsory. The status of a learning area in the curriculum ultimately has a bearing on the funds allocated towards the teaching of that particular learning area. Therefore, the researcher argues that a compulsory status for Geography will justify the time and resource investment in the subject in general and GIS in particular to a greater extent in Zimbabwe.

\section{Concluding Remarks}

In summary, this article examined the lessons that can be drawn on GIS implementation for Zimbabwe from the South African experiences. The findings indicated that GIS implementation in South Africa was curtailed by a multiplicity of challenges. The greatest challenge to GIS implementation as revealed by this article was a lack of funding. A lack of funding can be concluded to have an overarching bearing on other challenges which militate 
against GIS implementation. The researcher concludes that lack of funding feeds into other challenges such as class size and lack of electricity. Addressing the issue of funding in schools will arguably positively impact on provision of more infrastructure which in turn reduces class size. The article further established that GIS implementation was also affected by time allocation. The allocated four hours are not adequate to ensure sufficient coverage of GIS in Geography lessons. It was further noted that GIS needs to be integrated into Geography topics (as in South Africa) instead of being taught as a separate subject (as in the Zimbabwean approach). The article recommends that Geography as a learning area should be made compulsory. The researcher noted that in both countries Geography is offered as an elective. Thus, it can be argued that lack of funding and time allocation challenges can be addressed through a change in the elective status of Geography. Learning areas which are compulsory enjoy a bigger allocation of resources by schools and stakeholders. Additionally, the article established that GIS implementation in schools was affected by lack of electricity in some schools especially rural schools. The electricity challenge can be addressed through provision of alternative power sources such as solar energy to schools which are located away from the power grid. In view of the above discussed GIS implementation challenges, the author recommends the adoption of a paper-based GIS in schools in Zimbabwe. Despite the challenges highlighted in this article, the inclusion of GIS in the Geography syllabi in both Zimbabwe and South Africa is applauded for keeping up with the latest technological advancements worldwide.

\section{References}

Bowen, G.A. 2009. Document Analysis as a Qualitative Research Method. Qualitative Research Journal 9,2: 27 - 40.

https://doi.org/10.3316/QRJ0902027

Breetzke, G.D., S. Eksteen \& E. Pretorius 2011. Paper-based GIS: A Practical Answer to the Implementation of GIS Education into Resource-poor Schools in South Africa. Journal of Geography 110,4: 1 - 10.

http://hdl.handle.net/2263/19617

Burrough, P.A. 1986. Principle of Geographical Information Systems for Land Resources Assessment. Oxford: Clarendon.

Chisholm, L., U. Hoadley, M. wa Kivulu, H. Broakes, C. Prinsloo, A. Kgobe, 
D. Mosia, H. Narsee \& S. Rule 2005. Educator Workload in South Africa. HSRC Press. Cape Town.

Curriculum Development Unit 2015. Geography Syllabus (Forms 1 - 4). Harare: Ministry of Primary and Secondary Education.

Dardagan, C. 2013. Zimbabwe has a Thing or Two to Teach. The Mercury. https://www.iol.co.za/mercury/zimbabwe-has-a-thing-or-two-to-teach1464968

Darling-Hammond, L. 1998. Teacher Learning that Supports Student Learning. Educational Leadership 55,5: 6 - 11.

Drew, M. 2012. Neighbourly Lessons in Education. Mail and Guardian. https://mg.co.za/article/2012-01-20-neighbourly-lessons-in-education/

Gardner, D. \& D. Lambert 2007. Key Stage 3 Review Special. Teaching Geography 32,1.

Grol, R. \& M. Wensing 2004. What Drives Change? Barriers to and Incentives for Achieving Evidence-based Practice. Medical Journal Australia 180,6. Hooker, 1., R. Small, C. Humphreys, K. Hegarty \& A. Taft 2014. Applying Normalization Process Theory to Understand Implementation of a Family Violence Screening and Care Model in Maternal and Child Health Nursing Practice: A Mixed Method Process Evaluation of a Randomised Controlled Trial. Implementation Science 10,39. https://doi.org/10.1186/s13012-015-0230-4.

Jansen, J. 2017. SA can Learn a Thing or Two from Zimbabwe's Education System. Sunday Times. Opinion.

https://www.timeslive.co.za/ideas/2017-11-30-sa-can-learn-a-thing-ortwo-from-zimbabwes-education-system/

Kerski, J.J. 2003. The Implementation and Effectiveness of Geographic Information Systems Technology and Methods in Secondary Education. Journal of Geography 102,4: 128 - 137.

https://doi.org/10.1080/00221340308978534

Komlenović, D., E. Manić \& D. Malinić 2013. The Geographic Information System (GIS) in Secondary Education in Serbia. Perspectives in Education 31,1: 96 - 104.

Konyana, S. \& E.G. Konyana 2013. Computerization of Rural Schools in Zimbabwe: Challenges and Opportunities for Sustainable Development: The Case of Chipinge District, South-East Zimbabwe. African Journal of Teacher Education 2,2.

https://doi.org/10.21083/ajote.v3i2.2156 
Lam, C., E. Lai \& J. Wong 2009. Implementation of Geographic Information Systems (GIS) in Secondary Geography Curriculum in Hong Kong: Current Situations and Future Directions. International Research in Geographical and Environmental Education 18,1: 57 - 74.

https://doi.org/10.1080/10382040802591555

Marais, P. 2016. 'We can't believe what we see': Overcrowded Classrooms through the Eyes of Student Teachers. South African Journal of Education 36,2: $1-10$.

https://doi.org/10.15700/saje.v36n2a1201

May, C. \& T. Finch 2009. Implementation, Embedding, and Integration: An Outline of Normalization Process Theory. Sociology 43: 535 - 554. https://doi.org/10.1177/0038038509103208

May, C. 2013. Towards a General Theory of Implementation. Implementation Science 8,18: 1 - 14.

https://doi.org/10.1186/1748-5908-8-18

Ministry of Primary and Secondary Education 2015a. Curriculum Framework for Primary and Secondary Education 2015 - 2022. Harare: Ministry of Primary and Secondary Education.

Ministry of Primary and Secondary Education 2015b. Curriculum Review Process: Narrative Report 2014 - 2015. Harare: Ministry of Primary and Secondary Education.

Motshekga, A. 2010. Statement by the Minister of Basic Education, Mrs. Angie Motshekga, MP on the Progress of the Review of the National Curriculum Statement, Tuesday 06 July 2010. Available at: https://edulibpretoria.files.wordpress.com/2010/07/motshekgastatement-6-july-2010.pdf

Nxele, A. 2007. The Impact of the Transition from Grade 7 - 9 to FET (Grade 10 - 12) on the Teaching and Learning of Geography in Eastern Cape Schools. Paper presented at the Society of South African Geographers, Nelson Mandela Metropolitan University, Port Elizabeth.

Nziramasanga, C.T. 1999. Report of the Presidential Commission of Inquiry in Education and Training. Harare: Government Printers.

O'Leary, Z. 2014. The Essential Guide to Doing your Research Project. $2^{\text {nd }}$ Edition. Thousand Oaks, CA: SAGE Publications, Inc.

Ozgen, N. 2009. The Functionality of a Geography Information System (GIS) Technology in Geography Teaching: Application of a Sample Lesson. Educational Sciences: Theory \& Practice 9,4:1879 - 1894. 
Palladino, S. 1994. A Role for Geographic Information Systems in the Secondary Schools: An Assessment of the Current Status and Future Possibilities. Perspectives and Resources for GIScience Education. http://escholarship.org/uc/item/6p93g6wd

Stake, R.E. 1995. The Art of Case Study Research. Thousand Oaks, CA: Sage Publications

Tarisayi, K.S. 2010. An Investigation into the Challenges of Implementation of Computers in Rural Secondary Schools in Masvingo District. Unpublished Bachelor of Education dissertation. Gweru: Midlands State University.

West, B.A. 2003. Student Attitudes and the Impact of GIS on Thinking Skills and Motivation. Journal of Geography 102,6:267 - 274. https://doi.org/10.1080/00221340308978558

Whitaker, D. 2011. Using Geographic Information Systems in Science Classrooms. Educar em Revista, Curitiba, Brasil 40: 51 - 68. https://doi.org/10.1590/S0104-40602011000200005

Zucker, D.M. 2009. How to do Case Study Research. Teaching Research Methods in the Social Sciences 2: 1 - 17.

Zuma, S. 2016. Teachers' Reflections of Teaching Geographical Information System (GIS) at Grade 11 within CAPS in a Township School in the uMhlathuze Circuit. Unpublished Masters Thesis. University of KwaZulu-Natal.

Kudzayi Savious Tarisayi Postdoctoral Fellow Geography University of KwaZulu-Natal TarisayiK@ukzn.ac.za 